\title{
A Casa da Comédia (1946-1975) De Fernando Amado a Bertolt Brecht
}

\author{
Rui Pina Coelho
}

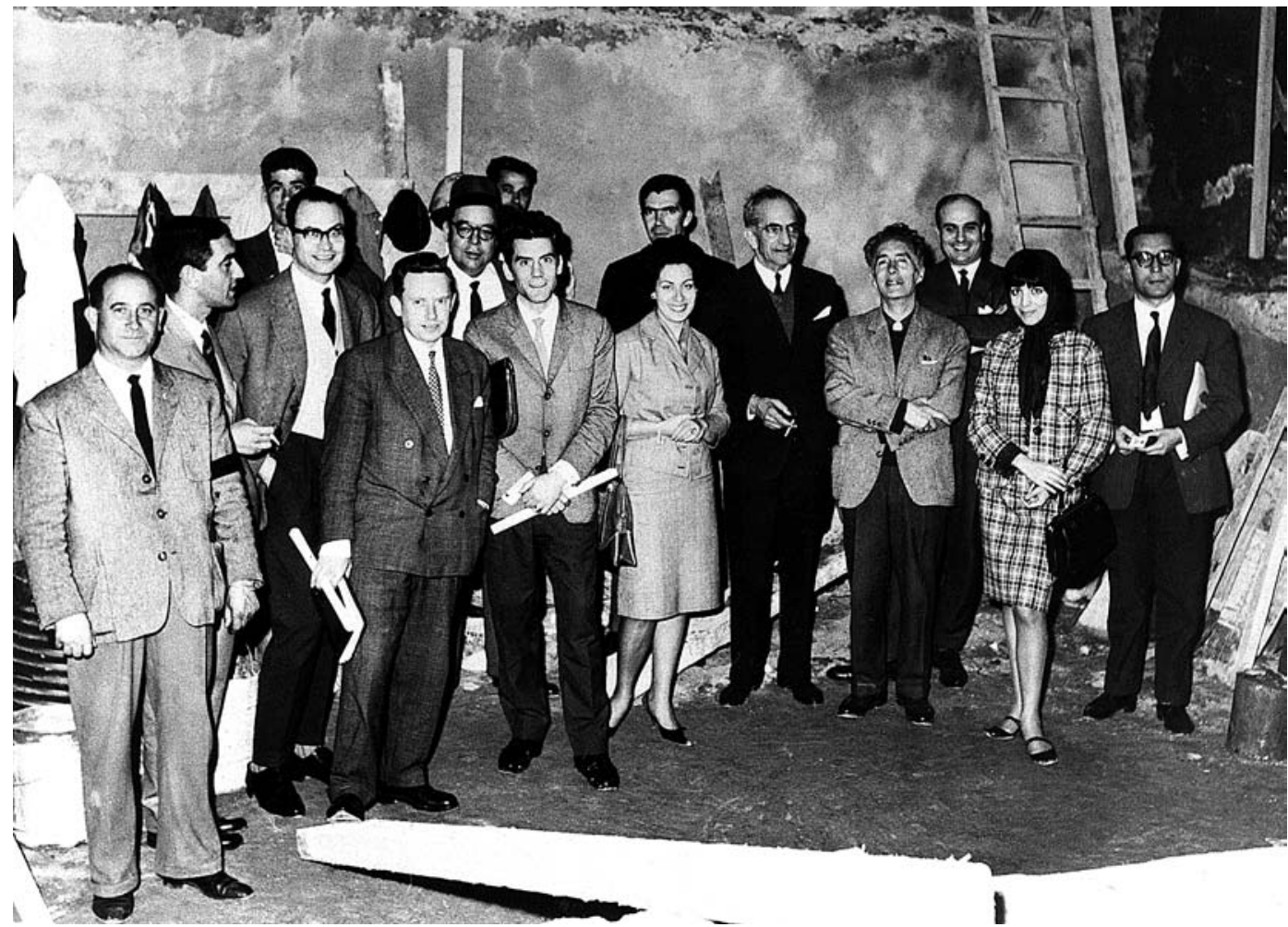

A Casa da Comédia, nas palavras de Fernando Amado (1899-1968), seu fundador e mentor, "nasceu como nascem todas as coisas bonitas. Nasceu quase sem sabermos como..." ${ }^{11}$. Contudo, a sua história tem que se contar a dois tempos.

0 primeiro tem origem na secção de teatro do Centro Nacional de Cultura intitulada Casa da Comédia, e traduzse em duas apresentações públicas: em Junho de 1946 e em Maio de 1947, no Teatro do Ginásio. Este grupo vai partilhar algumas afinidades estéticas com o movimento de teatro experimental que, no Portugal do pós-Segunda Guerra Mundial, se caracteriza por uma ânsia de renovação e actualização. São alguns intentos isolados, realizados sobretudo por amadores, que não ultrapassam o habitual reduto da classe intelectual lisboeta. Trata-se de um experimentalismo que se vai reflectir menos no arrojo de inovadoras propostas cénicas, do que numa atitude de divulgação de obras e autores, na valorização de uma ética em relação ao trabalho teatral, e na rejeição dos interesses comerciais e das convenções da profissão.

A Casa da Comédia, depois destas duas apresentações, acaba por desaparecer. Reaparece cerca de vinte anos depois, animada pelo mesmo director, com a mesma designação, mas desta feita como um grupo de teatro com um espaço próprio e com um núcleo de actores (amadores) relativamente estável, sendo este o segundo momento da sua história.

0 primeiro espectáculo da sua primeira fase de vida (1946/47) consiste numa apresentação única a 16 de Junho de 1946, no Teatro do Ginásio, do capricho teatral de Fernando Amado, A caixa de Pandora. De uma maneira geral, é recebido como uma "lufada de ar fresco" ${ }^{2}$. Adolfo Casais Monteiro, no Mundo Literário, escreve que "a representação de $A$ caixa de Pandora deve ser saudada como a mais animadora 'experiência' feita recentemente em palcos portugueses"

Animado por esta recepção, a 30 de Maio de 1947 o grupo volta a apresentar-se a público no mesmo teatro, desta vez com cinco textos de Fernando Amado: a reposição do capricho teatral A caixa de Pandora, precedida dos "debuchos teatrais" O meu amigo Barroso, Música na igreja e O ladrão, e do sainete Novo mundo. Em relação a este espectáculo, João Pedro de Andrade - que não assistira à primeira apresentação da Casa da Comédia - declara
Grupo inicial e alguns colaboradores da Casa da Comédia nas obras do futuro Teatro de Bolso de Lisboa, 1962, fot. Elo.

Citado em "Numa antiga carvoaria transformada em Teatro de Bolso apresenta-se hoje o Clube de Teatro Casa da Comédia", Diário Popular, 18-07-1963.

Adolfo Casais Monteiro "A caixa de Pandora capricho teatral em um acto, de Fernando Amado", Mundo Literário n. 8 , 29-6-1946. 


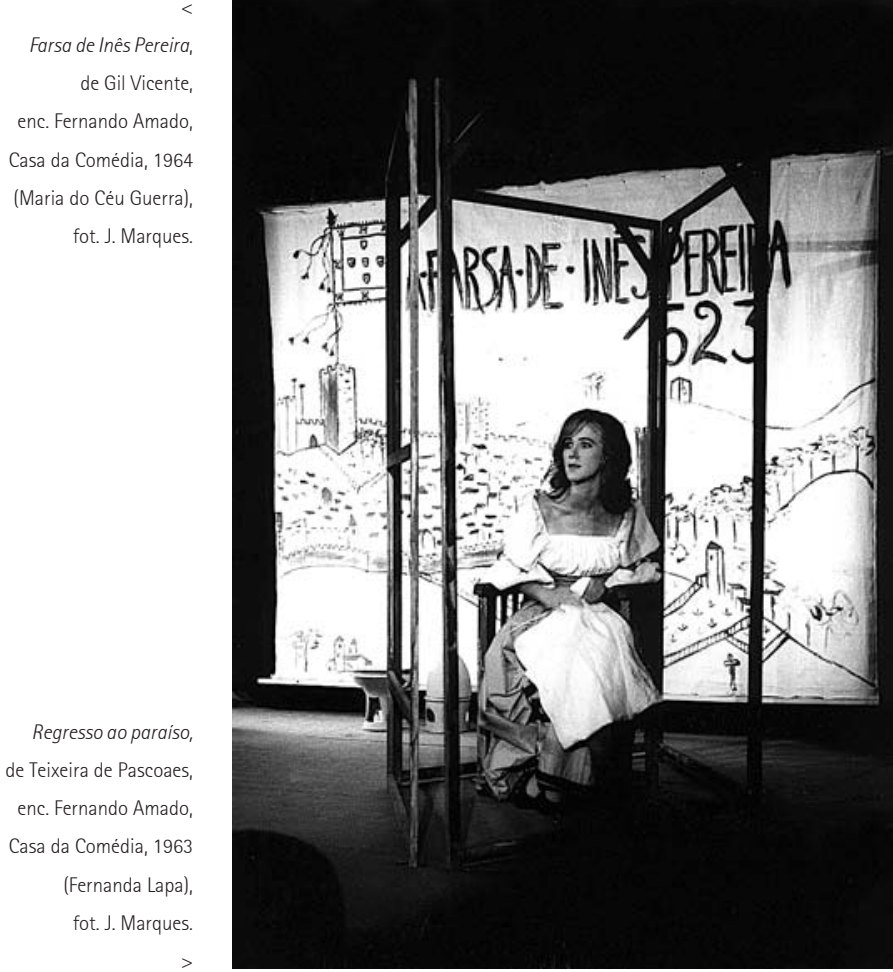

que a reposição de A caixa de Pandora, a um ano de distância, não é oportuna. Para além disso, sendo um autor e um crítico teatral animado pelo mesmo espírito de renovação teatral que presidia às iniciativas da Casa da Comédia, declara que o texto de Amado não Ihe pareceu "suficientemente convincente na doutrina nem na forma como está exposta"4.

0 que ressalta da recepção a estes espectáculos é a expectativa criada e a exigência que é posta em relação aos chamados grupos experimentais. Embora algumas apresentações tenham resultado em espectáculos mais frágeis, ressalva-se "o renascimento do amor pelo teatro em pequenas iniciativas puras, aparentemente ingénuas" ${ }^{4}$ que se contraporiam à futilidade e ao comercialismo da maioria do teatro profissional.

A Casa da Comédia enquanto grupo de teatro com sede própria é fundada em 1962, mas as suas portas só são abertas em Julho de 1963. Entre estas duas datas são feitas as obras que transformam uma antiga carvoaria numa sala de teatro. É assim que na Rua S. Francisco de Borja, n. ${ }^{\circ} 24$, às Janelas Verdes, nasce o que vai ser uma das mais estimulantes salas de espectáculo de Lisboa: o Teatro de Bolso de Lisboa - Casa da Comédia. A escolha do espaço é motivada por um discreto anúncio num jorna lisboeta: "Barracão precisa-se com área aproximada de $150 \mathrm{~m} 2$ ". 0 que se irá aí construir é um pequeno Teatro de Bolso, decorado por José de Almada Negreiros, com capacidade para cerca de 100 espectadores, com um palco de 6,30 por 7 metros, caixa para orquestra, camarins sobre o palco, apto também como sala de conferências.

Destinava-se a ser uma oficina teatral onde se pudesse "experimentar" sem pressões de tempo. Muitos dos que então se reúnem em torno de Fernando Amado virão a ser figuras proeminentes do teatro contemporâneo em Portugal, como Fernanda Lapa, Manuela de Freitas, Maria do Céu Guerra, Santos Manuel, Glória de Matos, entre muitos outros.

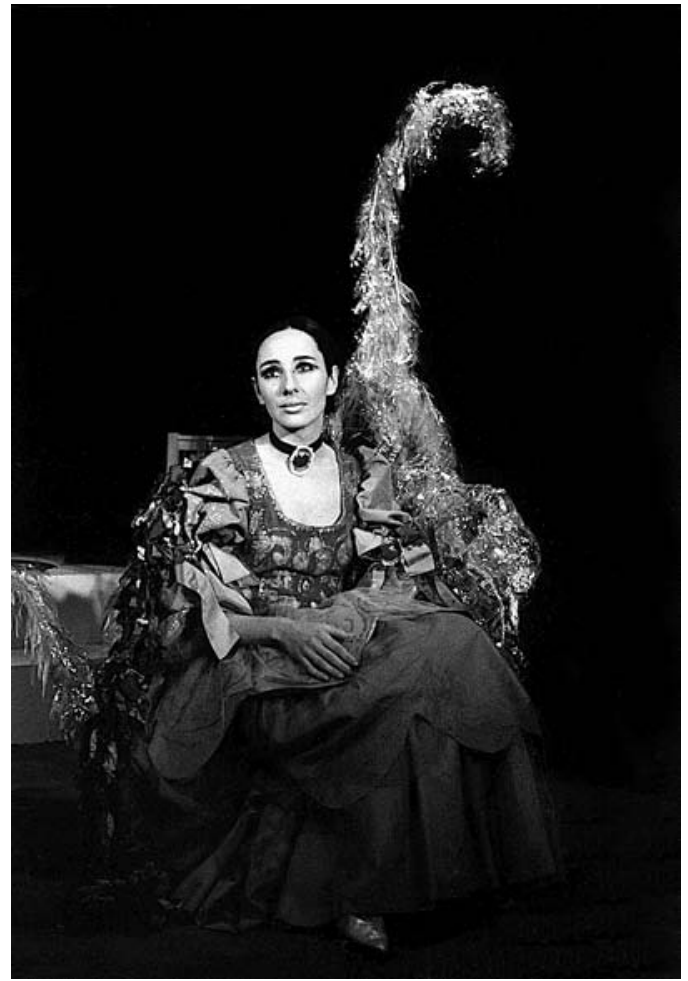

No início da actividade, sem subsídios de qualquer espécie, a actividade da Casa da Comédia era suportada pela cotização dos sócios. Não sendo cobrados bilhetes nem havendo folha de pagamentos, era magro o orçamento, mas era dele que se faziam pagar as despesas de funcionamento como a electricidade, os cenários ou os programas. Este amadorismo, partilhado por muitos colectivos seus contemporâneos, é, regra geral, sinónimo de experimentalismo. Num quadro onde até o teatro comercial - que dominava a cena portuguesa - se encontra ameaçado pela falta de espectadores, Fernando Amado não hesita em proclamar: "Aqui podemos fazer teatro autêntico, teatro de vanguarda" ${ }^{\text {. }}$. Reclamando uma liberdade estética e repertorial, o seu "programa de trabalho" deixa entrever alguns eixos norteadores da sua actividade. E não é pequeno o cometimento quando chamam a si objectivos tão vastos como: revelar e representar novos autores portugueses, levar à cena autores portugueses clássicos e modernos; apresentar autores estrangeiros que possam valorizar culturalmente a dramaturgia portuguesa; criar uma Escola de Formação de Arte de Teatro; realizar conferências e palestras por autores, encenadores, críticos ou ensaístas, nacionais e estrangeiros; apresentar espectáculos de qualidade destinados aos mais diversos tipos de público (tais como operários fabris, aglomerados agrícolas ou associações recreativas), fazendo acompanhar essas representações de prévias explicações dos temas tratados e das noções gerais da arte cénica; estabelecer intercâmbios com instituições teatrais, nacionais e estrangeiras, com o fim de promover a aprendizagem teatral dos seus associados; promover e facilitar a presença de actores e técnicos em festivais de teatro nacionais e estrangeiros; para além da publicação de um boletim mensal e da obtenção de descontos para os seus sócios noutros espectáculos em Portugal.

Para a inauguração do novo espaço são escolhidos Verbo escuro Regresso ao paraíso de Teixeira de Pascoaes, 


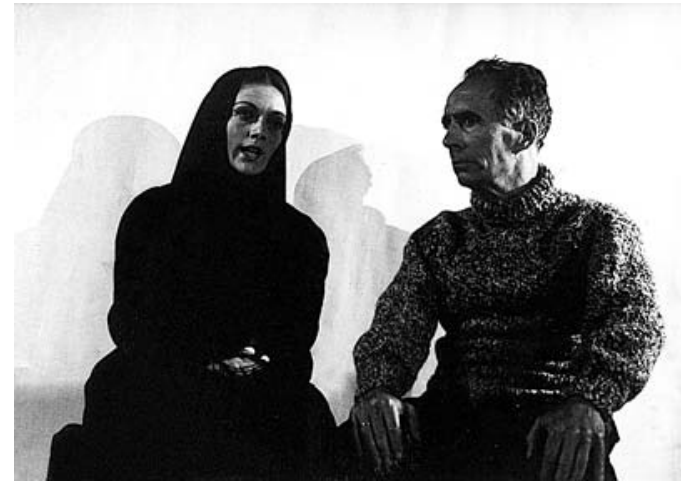

estreados a 19 de Julho de 1963. 0 espectáculo, que consistia na dramatização de nove poemas de Teixeira de Pascoaes e na representação em pantomima de Regresso ao paraiso, é saudado pela imprensa, sobretudo, por três motivos: pela inauguração de um novo espaço teatral para a cidade, pela feliz escolha dos textos e pelo desempenho do colectivo. 0 facto de na estreia se ter optado pela encenação de poemas revela uma preocupação singular com uma linguagem teatral não divorciada das qualidades poéticas. Trata-se da procura do "essencialismo" teatral em que o poder evocativo da palavra substitui outros recursos técnicos. É ainda de realçar a maior intimidade com o espectador - apanágio de um teatro de bolso -, e a centralidade do encenador. A "poesia em cena" exige, com efeito, um local puramente teatral, o que parece ser a definição da própria Casa da Comédia.

Idêntica argumentação justifica a encenação de poemas de Jean Cocteau na homenagem que a Casa da Comédia Ihe faz. Fernando Amado encena, do poeta francês, 0 monólogo 0 mentiroso e o poema dramático 0 pobre marujo (Abril de 1964), intervalados pela declamação de vários poemas por Maria do Céu Guerra. A presença da palavra poética no repertório da Casa da Comédia materializa-se também noutras actividades aí realizadas, tais como recitais, conferências subordinadas a este tema e palestras com poetas.

0 valor da poesia em cena liga-se com outro dos eixos estruturantes do repertório do grupo nesta sua segunda fase de existência (1962-65): a montagem de textos originais encenados pelos seus próprios autores. Para além dos pequenos textos de Fernando Amado (O pensador, Descobri uma estrela e 0 iconoclasta), são apresentados em encenação dos seus autores, no Verão de 1964, a Invenção da descoberta de José d'Orey e, de Francisco de Seara Cardoso, A reconstituição e As avestruzes. Ainda sem obra publicada, estes autores viam na colaboração com o grupo uma forma de dar a conhecer a sua escrita.

A dimensão poética do texto é também o que justifica, e desta vez já com a direcção de Fernando Amado, a escolha de Loa para o Auto do Divino Narciso (Fevereiro de 1964) de Soror Juana Inez de la Cruz, um diálogo alegórico entre o Zêlo, a Religião, o Ocidente e a América, que é mote para pôr em cena a conquista do México Azteca e as suas nefastas consequências civilizacionais.

0 apego à depuração e à ausência de artifícios cénicos, aliado a uma atitude pedagógica para com os actores e demais colaboradores, é também o que explica a significativa presença de Gil Vicente nesta fase da Casa da Comédia.

Ainda antes do espectáculo todo ele dedicado ao clássico português - Recital vicentino (Setembro de 1964) -, Amado

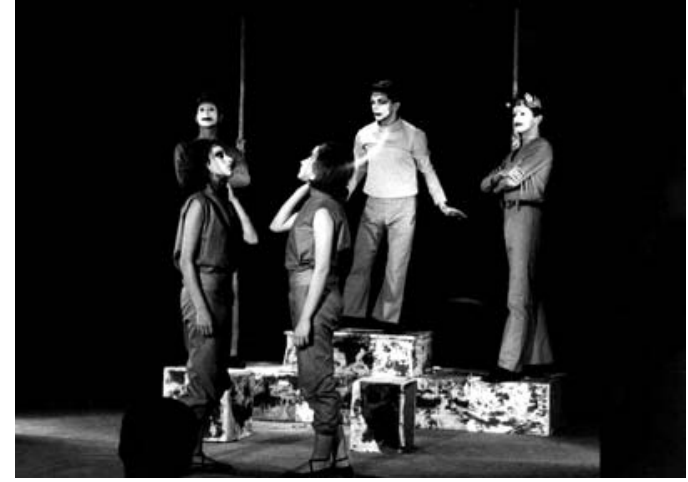

Opensador,

texto e enc.

Fernando Amado,

Casa da Comédia, 1963 (Manuela de Freitas e Fernando Amado), fot. J. Marques.

encena o Auto da Índia, Os mistérios da Virgem [do Auto de Mofina Mendes] e a Farsa de Inês Pereira. Apresentados em conjunto com outros textos, são como que a preparação para um grande espectáculo vicentino.

A constituição do repertório da Casa da Comédia sob a direcção de Fernando Amado faz-se igualmente com textos representantes de uma dramaturgia moderna. $\mathrm{E}$ neste capitulo incluem-se Deseja-se mulher (Novembro de 1963), e Antes de começar (Dezembro de 1964), ambos de Almada Negreiros, apresentando-se este último lever de rideau juntamente com 0 iconoclasta ou o pretendente imaginário de Amado (Dezembro de 1964), como "um recital de teatro moderno".

0 ano de 1965 marca um periodo de transição na Casa da Comédia. A partir desta data, Fernando Amado, por motivos de saúde, afasta-se progressivamente dos trabalhos. Contudo, nesse ano, ainda supervisiona a encenação do jovem Filipe Ferrer de Médico à força, de Molière, e d' O baile dos mercadores, do seu colaborador e cúmplice João Osório de Castro, assistido por Luís Sande Freire. Pela primeira vez, Ferrer, que já antes tinha colaborado com o grupo enquanto actor, assume neste espectáculo a função de encenador. Esta "descentralização" vai marcar de maneira indelével a vida da Casa da Comédia depois da morte do seu fundador e principal animador.

A terceira fase de vida da Casa da Comédia (196575) tem início com Morte e vida Severina (Janeiro 1965) de João Cabral de Melo Neto, dirigido pela encenadora brasileira Maria Barreto Leite e com a participação de muitos nomes novos, como foi o caso de Filipe La Féria e de Vicente Galfo. Entretanto, sem a figura tutelar de Fernando Amado por perto, muitos são os que se afastam do grupo, procurando novas experiências, embora alguns, mais tarde e em diferentes contextos, regressem à pequena oficina de teatro que os fez actores. Nesta terceira fase, as encenações deixam de ter a (quase) exclusividade de uma só mão, passando a envolver outros elementos: uns, colaboradores próximos do grupo, descobrem na encenação uma outra componente do trabalho teatral; outros respondem a convites da direcção, trazendo consigo uma pluralidade de olhares e experiências; outros ainda, chegando de fora à Casa da Comédia, por lá vão ficando, descobrindo nesta "Casa" um espaço aberto à experimentação. De toda esta panóplia, dois nomes se destacam, quer pelo número de encenações que realizaram com o grupo, quer pela projecção que vão alcançando no panorama teatral português: Norberto Barroca e Jorge Listopad.

Mas ainda antes do primeiro trabalho nesse campo de Norberto Barroca, a Casa da Comédia apresenta, em
Invenção da descoberta texto e enc. José d'Orey, Casa da Comédia, 1964, fot. J. Marques. 
cento e vinte e quatro $\mid$

Sinais de cena 6.2006 $\mid$ Arquivo Solto

Rui Pina Coelho

A Casa da Comédia (1946-1975): De Fernando Amado a Bertolt Brecht

A reconstituição, texto e enc. Francisco de

Seara Cardoso,

Casa da Comédia, 1964 (Manuela de Freitas e Norberto Barroca), fot. J. Marques.

Baile dos mercadores, de João Osório de Castro, dir. art. Fernando Amado, ass. real. Sande Freire Casa da Comédia, 1965 (João Silva

e António Rama),

fot. J. Marques.

Morte e vida Severina de João Cabral de Melo Neto, enc. Maria Barreto Leite, Casa da Comédia, 1966

fot. J. Marques.

Noites brancas

de Dostoievski, enc. Norberto Barroca, Casa da Comédia, 1967

(Graça Lobo Wladimir Franklin

e Noberto Barroca),

fot. J. Marques.
Dezembro de 1966, Zé Broa no Far-West de Francisco Esteves, encenado pelo autor, e Os demandistas (Les plaideurs) de Racine, com encenação de Serge Farkas. A história de Zé Broa e do seu burro Catraio, que se vêem enredados num problema de heranças, bandidos e xerifes, é um espectáculo de teatro para a infância, antecedido por duas experiências de fantoches, e traz consigo a génese daquelas que são duas das vertentes importantes do grupo nesta sua terceira fase de vida: o teatro para a infância e o teatro de marionetas.

Nos finais de 1966, Fernando Amado, já fragilizado pela doença, ainda inicia os ensaios de A cabeça de Baptista e Sacrilégio, de Valle Inclán, no âmbito das comemorações do centenário do nascimento deste autor. Contudo, tal intento não vai avante. A sua derradeira aparição no palco da Casa da Comédia será na estreia d' Os demandistas, antes do pano subir, onde vem explicar a intenção de dar à peça a roupagem e o estilo da commedia dell'arte italiana.

Em Fevereiro de 1967, Norberto Barroca, colaborador de longa data de Fernando Amado, estreia-se na encenação com Noites brancas, uma adaptação do conto homónimo de Dostoievski. Este é o primeiro de uma série de espectáculos encenados por Norberto Barroca, que se torna assim um dos principais executantes da ideia teatral do grupo e também aquele que está mais próximo do legado do seu Mestre. Na sua segunda encenação, é ainda mais fácil reconhecermos a herança de Fernando Amado: À procura da verdade, uma homenagem a Pirandello (Janeiro 1968), na qual, entre outros textos coligidos pelo encenador, se representam a peça em um acto 0 torno e Sonho... mas talvez não. Trata-se de um tributo à "estrela maior" da "constelação de referências" da Casa da Comédia.

A terceira encenação de Barroca para a Casa da Comédia faz-se sob o signo da urgência. A equipa da Casa da Comédia acelera os ensaios de A caixa de Pandora, trabalhando ainda com Amado no início dos trabalhos, naquela que seria uma justa homenagem ao mentor do grupo. Mas a morte nunca atende aos ritmos dos ensaios de teatro e Fernando Amado, a 23 de Dezembro de 1968, parte. A caixa de Pandora, a sua peça-manifesto, só estreará em Março de 1969. Este será, então, o primeiro espectáculo da Casa da Comédia após a morte do seu fundador. No programa, a dimensão de tributo assume letra grande. Afonso Botelho, Victor Silva Tavares, João Osório de Castro e Norberto Barroca deixam aí linhas emocionadas, evocando a estreia deste texto no Teatro do Ginásio e o legado artístico e humano que Amado deixou em cada um deles.

Norberto Barroca, em 1969, encena ainda mais dois espectáculos: Fando e Lis, a caminho de Tar, de Arrabal, e, de José Régio, Mário ou eu próprio, o outro, ambos com
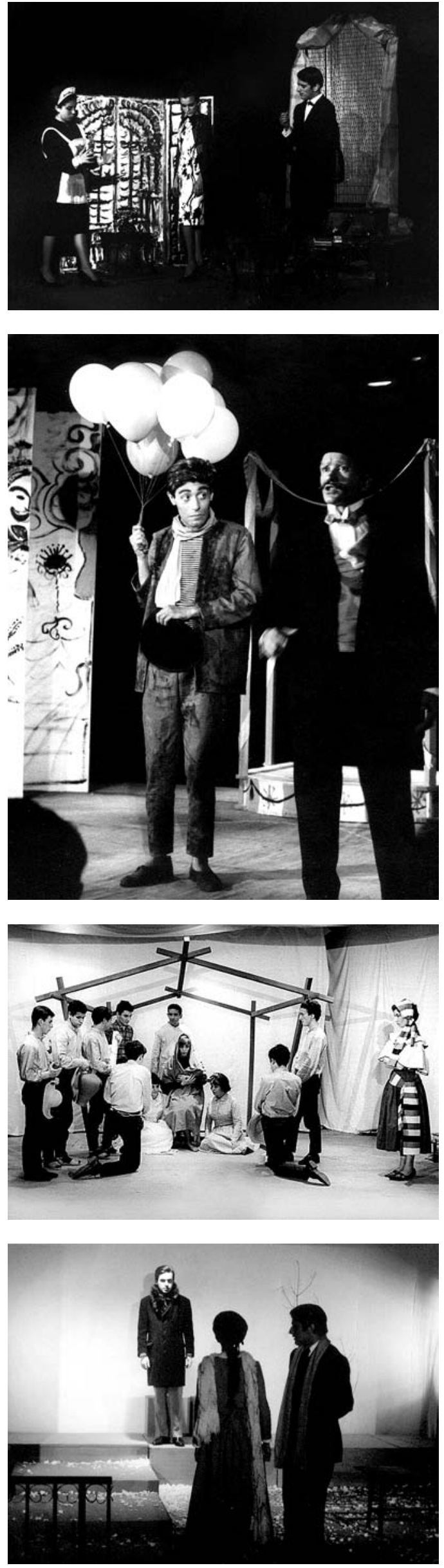

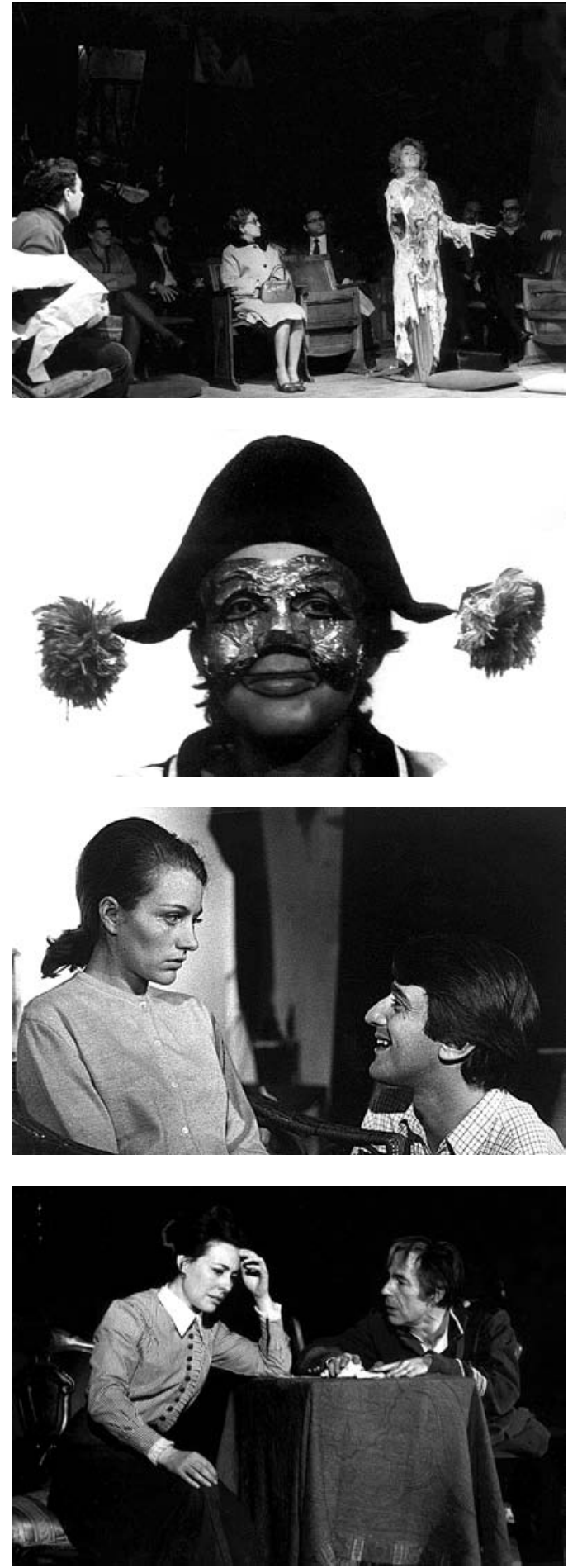

estreia em Outubro desse ano. A escolha de Arrabal, porventura facilitada por este ser um teatro de projecção limitada, não é, seguramente, alheia ao interesse que, pelos finais dos anos sessenta, alguma cena portuguesa mostra pelo teatro do absurdo ou de matriz surrealista, onde pontuam os nomes de Beckett, Pinter ou lonesco. Este interesse não é, como é óbvio, exclusivamente nacional: Samuel Beckett recebe, em 1969, o Prémio Nobel da Literatura. Mas em Portugal, aquele que seria o "concorrente" directo desta linhagem teatral, o teatro épico, tinha mais dificuldade em chegar aos palcos, dada a acção da censura. Assim, era pela via do absurdo que se podia ir construindo um elíptico discurso crítico.
0 Fando e Lis de Fernando Arrabal merece o seguinte comentário de um censor da Comissão de Exame e Classificação de Espectáculos: "não compreendo seguramente o seu alcance e significado, melhor, a sua mensagem, se é que a tem" ${ }^{17}$. Mas, se o censor não percebeu, Norberto Barroca, captou bem o seu sentido. No programa do espectáculo declara: "É muito difícil chegar a Tar impossivel mesmo -, mas quando se tem por que lutar, talvez o caminho se torne mais fácil. É preciso continuar, e não destruirmos os nossos próprios sonhos" ${ }^{18}$.

Mário ou eu próprio, o outro é uma homenagem a Mário de Sá-Carneiro, e consiste numa selecção de poemas do poeta e na representação da peça de Régio. Espectáculo modesto, é o regresso da poesia e da geração do Orpheu à Casa da Comédia, local onde foram sempre tão bem recebidas por Fernando Amado. Será com esta encenação que Barroca terminará uma série de trabalhos com o grupo. De todos os encenadores que colaboraram com o grupo nesta terceira fase de vida, Barroca foi o mais profícuo e aquele em que se pode observar com mais clareza a herança do ideário teatral de Fernando Amado.

Em 1968, a Casa da Comédia abre-se enquanto espaço de experimentação a elementos exteriores ao habitual círculo de colaboradores: Glicínia Quartin, Artur Ramos, Ruy Furtado e João Abel Manta vêm ai estrear Dias felizes, de Samuel Beckett, em tradução de Jaime Salazar Sampaio. Apesar de, na equipa técnica do espectáculo, estarem, em posições de assistência, elementos regulares do grupo Norberto Barroca (montagem), Rui Anjos/ Filipe La Féria (assistência) - a Casa da Comédia assume aqui a qualidade de entidade que acolhe um trabalho exterior. Não obstante isto, Dias felizes entra para o repertório do grupo.

Na mesma linha repertorial, a Casa da Comédia apresentará em Maio de 1970, Batalha naval, de Salazar Sampaio, com encenação de um estreante, Victor Poitout. 0 texto em que dois supostos náufragos esperam o regresso à civilização, numa suposta ilha deserta, jogando um interminável jogo de "batalha naval", herda o absurdo de situações criadas por autores como Beckett, Pinter ou Ionesco, fazendo da Casa da Comédia palco dilecto deste género teatral.

Mas voltemos cronologicamente um pouco atrás, ao ano de 1969 - ano de grande actividade para a Casa da Comédia. Para além das três encenações de Norberto Barroca, estreia também A dança da morte, de August Strindberg (Maio de 1969), com encenação de Jorge Listopad, um espectáculo que vai ser considerado um dos acontecimentos mais significativos desse ano teatral. É a primeira de quatro encenações de Listopad com o grupo das Janelas Verdes. 0 encenador e os actores que compõem
O fim,

de António Patricio, enc. Jorge Listopad, Casa da Comédia, 1971 (Manuela de Freitas e Vasconcelos Viana), fot. J. Marques.
A caixa de Pandora, de Fernando Amado, enc. Norberto Barroca, Casa da Comédia, 1969 (Carlos Paulo), fot. J. Marques.

Fando e Lis, a caminho de Tar,

de Fernando Arrabal, enc. Norberto Barroca, Casa da Comédia, 1969 (Manuela de Freitas e Norberto Barroca), fot. J. Marques.

A dança da morte, de August Strindberg, enc. Jorge Listopad, Casa da Comédia, 1969 (Carmen Dolores

e Augusto de Figueiredo) fot. J. Marques.

${ }^{7}$ Registo no 8869 da Comissão de Exame e Classificação de Espectáculos / Inspecção dos Espectáculos -

Secretaria de Estado da Informação e Turismo | Direç̧ão do Serviço de Espectáculos, consultado na Torre do Tombo e no Museu Nacional do Teatro.

${ }^{8}$ Norberto Barroca no programa do espectáculo Fando e Lis (1969). 


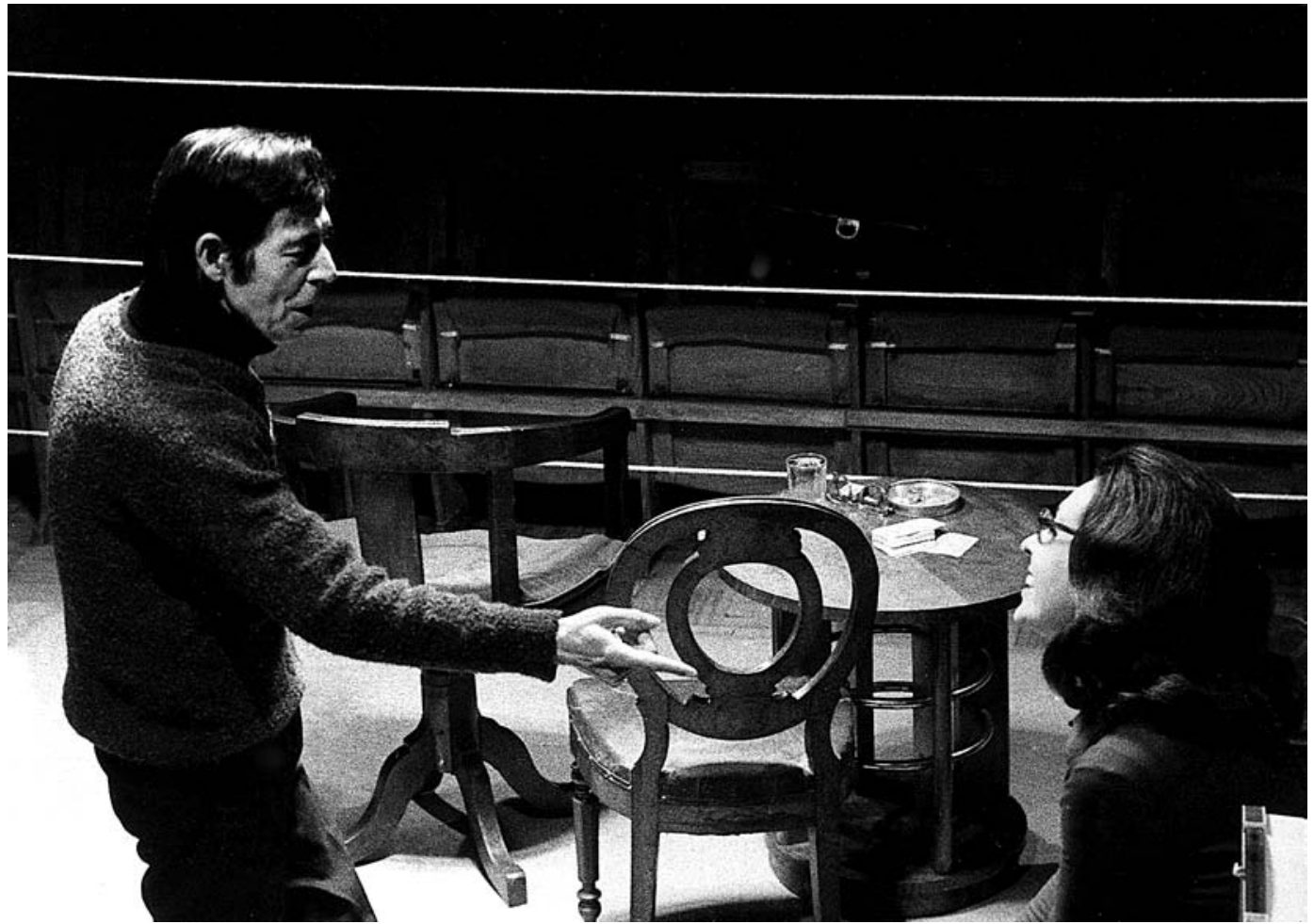

a equipa de trabalho chegam mais uma vez de fora do habitual círculo de colaboradores, seduzidos pela experimentação que ai se permite. 0 elenco reúne Carmen Dolores, Augusto de Figueiredo e Álvaro Benamor, actores de crédito reconhecido na cena nacional.

A segunda encenação de Jorge Listopad para a Casa da Comédia é $O$ fim, de António Patrício (Abril 1971), naquela que é a estreia deste texto em palco. A colaboração deste encenador com a Casa da Comédia vai ainda resultar em mais dois espectáculos: Dança da morte em doze assaltos, de Friedrich Dürrenmatt (Março de 1972) e Alice nos Jardins do Luxemburgo, de Romain Weingarten (Dezembro de 1972). 0 primeiro surge pelo convite da Fundação Calouste Gulbenkian para repor o texto de Strindberg, após o êxito alcançado três anos antes, no sentido de integrar o III Ciclo Gulbenkian de Teatro (1972). Reúnem-se os mesmos actores, mas decide-se não apresentar o texto do autor sueco, mas sim Play Strindberg, de Dürrenmatt, subtitulando-o em português Dança da morte em doze assaltos. Por sua vez, Alice nos jardins do Luxemburgo, de Romain Weingarten (Dezembro 1972), pela primeira vez apresentado em Portugal, é a última colaboração de Listopad com a Casa da Comédia. As suas encenações em muito vêm contribuir para que esta seja reconhecida como um espaço aberto a projectos experimentais, tornando-se um dos palcos mais interessantes da capital.

Os trabalhos de Norberto Barroca e Jorge Listopad constituem o mais significativo do repertório da vida da Casa da Comedia após a direcção de Fernando Amado. Contudo há vários encenadores que, um pouco mais avulsamente, ai descobrem espaço aberto para projectos pessoais e de experimentação. Logo em 1967 (Maio), Manuela Machado traduz, adapta e interpreta as cartas de Mariana Alcoforado, em Soror Mariana, a freira de Beja, um espectáculo assinado por Francisco Relógio e Filipe La Féria. É o mesmo o caso de Olho de giz, de Tone Brulin
(Julho de 1967), autor que voltará à Casa da Comédia, em 1969, para ministrar um curso sobre o "teatro pobre de Grotowsky". Também João Osório de Castro, que assumira o papel de director do grupo, decide, em Dezembro de 1970, tentar a encenação, dando cumprimento a uma ideia não concretizada de Fernando Amado: a representação de peças em um acto de Ramon del Valle-Inclán: $A$ cabeça do Baptista, Laço de sangue e Sacrilégio.

Em Janeiro de 1972, pela mesma altura em que os Bonecreiros - Teatro Laboratório de Lisboa estreiam o seu primeiro espectáculo - O circo imaginário do Super-Basílio, de Béatrice Tanaka (enc. João Mota, Dez. 1971) - e lonesco vem a Lisboa proferir uma conferência no Grémio Literário (a 1 de Fevereiro) e assistir à apresentação do seu 0 rei está a morrer (Cia. Rey Colaço/ Robles Monteiro, enc. Amélia Rey Colaço, Fev. 1972), Fernando Arrabal volta ao palco da Casa da Comédia pela mão de Herlander Peyroteo, um nome habitualmente ligado à tele-encenação e que já participara em vários espectáculos de Fernando Amado. Depois da apresentação de Beckett, Strindberg, Arrabal, Salazar Sampaio, Valle Inclán e Patrício (e uns meses antes de Dürrenmatt e Weingarten), este espectáculo ajuda a consolidar o teatro do absurdo, ou de matriz surrealista (ou, na formalização de Arrabal: "teatro de cerimonial" ou "teatro pânico", como hóspede permanente da Casa da Comédia. 0 espectáculo é composto por Os quatro cubos e Uma tartaruga chamada Dostoievski.

0 ano de 1972 vai ser um ano muito profícuo no pequeno teatrinho das Janelas Verdes. Logo depois das apresentações das duas peças de Arrabal, durante o mês de Março, Play Strindberg anda pelo país integrado no III Ciclo Gulbenkian de Teatro, chegando à Casa da Comédia em Abril. Isto obriga a que uma outra parte do grupo ensaie na sala de festas da Sociedade Ordem e Progresso Desejase mulher, de Almada Negreiros, estreando em Junho na sala do grupo. Umas semanas depois, estreia-se $A$ chançada d'a vida do grande D. Quixote de la Mancha e do gordo 


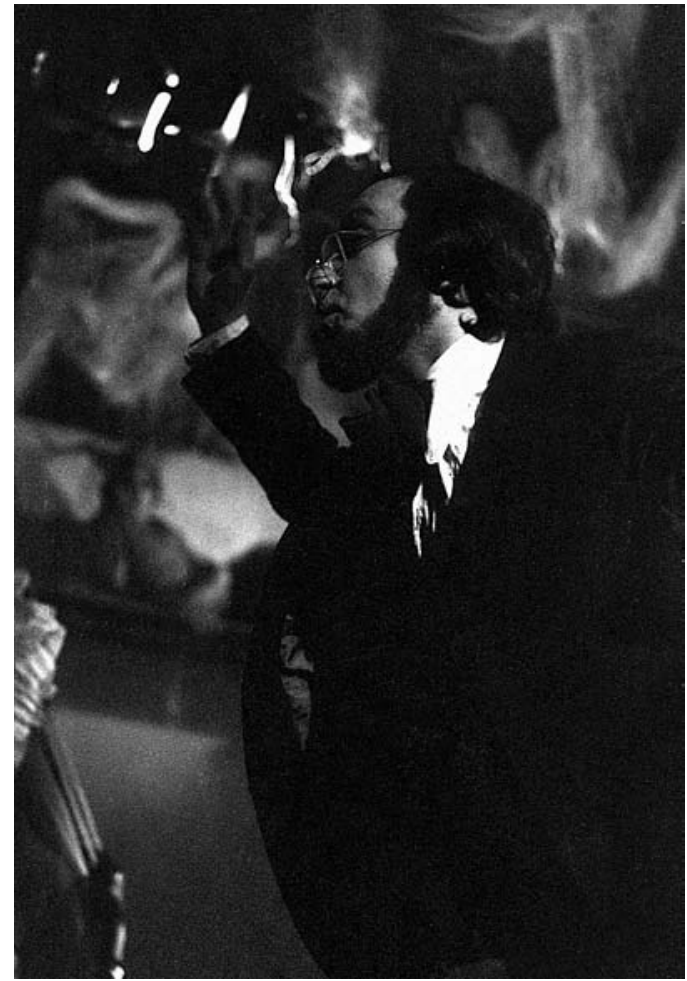

Sancho Pança, de António José da Silva, no Palácio Galveias, em Lisboa. E o ano não terminará sem que a Casa da Comédia apresente Leôncio e Lena, de Büchner, e Alice nos jardins do Luxemburgo, de Weingarten. Muito para um pequeno teatro experimental, como adiante se verá.

Deseja-se mulher, é uma homenagem ao mestre modernista (que morrera em 1970) - assinalando a décima temporada da Casa da Comédia e o décimo aniversário da estreia deste mesmo texto pela mão de Amado. Tem agora encenação de Fernanda Lapa, naquele que é o seu "regresso a casa". Mais do que em qualquer outro espectáculo desta terceira fase da Casa da Comédia, sente-se uma aproximação à época em que Fernando Amado dirigia o grupo, ainda que em interpelação desafiadora.

Entretanto, o espectáculo sobre a peça do Judeu é apresentado ao ar livre, nos jardins do Palácio Galveias, recriando-se um ambiente de feira e carnaval. No ano de 1972, esta é a segunda encenação de que o texto do Judeu é alvo: a primeira é a de Joaquim Benite, para o Grupo de Teatro do Campolide Atlético Clube. Estes dois espectáculos são pretexto para que, na imprensa, se dê a perceber (uma vez mais) a reivindicação por um teatro mais politizado terreno em que a Casa da Comédia decididamente não se movia, mas que inspirava indiscutivelmente o trabalho de Benite. Embora, de uma maneira geral, se elogiasse a realização plástica das Galveias, plena de cor e movimento, bem como alguns achados de encenação, acabava por ser motivo de desilusão a ausência de uma construção crítica sobre a actualidade. 0 jovem crítico Jorge Silva Melo escrevia: "tudo se amontoa e nada se compreende em Peyroteo: tudo se explica e tudo se chama para a nossa actualidade social em Benite" .

E era verdade que o trabalho na Casa da Comédia se pautava mais pela pesquisa artística e por um teatro que não encontrava no social a sua motivação. la-se mantendo, tanto quanto era possivel, alheado dos ventos que, no Portugal de 1972, anunciavam já outras marés.
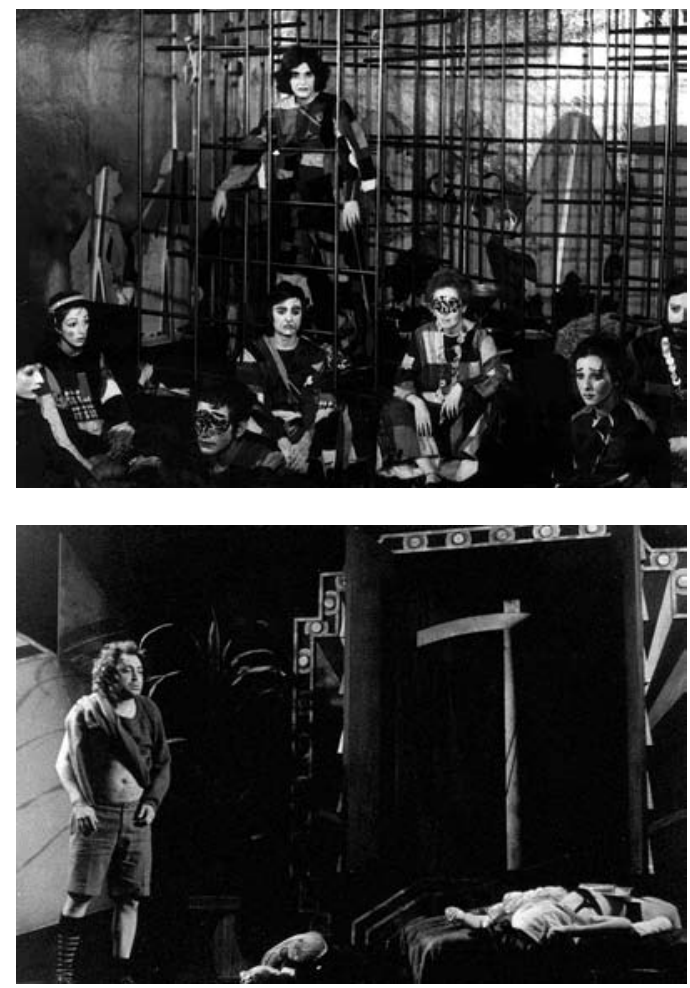

É essa mesma linha que preside à apresentação de Leôncio e Lena, de Georg Büchner, em encenação de Carmen Gonzalez - um projecto adiado desde 1968. A realização obedece mais a um desejo de colmatar uma lacuna no repertório nacional do que estabelecer um diálogo crítico com o quotidiano. Em Janeiro de 1974, Beckett volta a passar pelo palco da Casa da Comédia com Pantomimas em preto e branco, um espectáculo do argentino Júlio Castronuovo. É a segunda vez que Castronuovo se apresenta neste espaço, depois de aí ter apresentado Fim de festa, também do autor irlandês, numa encenação para o Teatro Experimental do Porto (TEP), em Março de 1971. Mas nestes espectáculos a Casa da Comédia tem somente papel de sala de acolhimento, não tendo nenhuma participação na sua produção. Já não é esse o caso de Oh papá, pobre papá, a mamã pendurou-te no armário e eu estou tão triste..., do norte-americano Arthur Kopit (Fevereiro de 1973), na primeira encenação daquele que virá a ser um dos mais reputados encenadores portugueses, João Lourenço. Sem ceder à tentação do comercialismo, Lourenço consegue um êxito de público e da crítica - pela primeira vez na história do grupo das Janelas Verdes. Os encómios à sua encenação não conhecem moderação. A carreira deste espectáculo só é interrompida para se estrear Doroteia, do brasileiro Nelson Rodrigues, com encenação de Morais e Castro. Estávamos em Março de 1974, um mês antes de Abril. 025 de Abril de 1974 mudava o País e, naturalmente, o seu teatro. A actualização e a renovação teatral, tão sonhadas por diferentes gerações de fazedores teatrais, tinham finalmente as portas abertas.

Mas voltemos, por uns parágrafos apenas, de novo aos tempos do periodo anterior a essa data, para darmos conta, mais detalhadamente, de duas vertentes dos interesses da Casa da Comédia nesta sua terceira fase de vida: o teatro para a infância e o teatro de marionetas.

0 primeiro destes interesses - 0 teatro para a infância - para além de Zé Broa no Far-West, de Francisco Esteves
Leôncio e Lena de Georg Büchner, enc. Carmen Gonzalez, Casa da Comédia, 1972, fot. J. Marques.

Os quatro cubos \& Uma tartaruga chamada Dostoievski, de Fernando Arrabal, enc. Herlander Peyroteo Casa da Comédia, 1972 (Jorge Vale), fot. Fotolucas.

Oh papá, pobre papá..., de Arthur Kopit, enc. João Lourenço, Casa da Comédia, 1973, (Jorge Vale e Lia Gama), fot. J. Marques.

Jorge Silva Melo, "2 Sanchos, 2 Quixotes", Critica, n. 9 9, Julho 1972 , p. 6. 


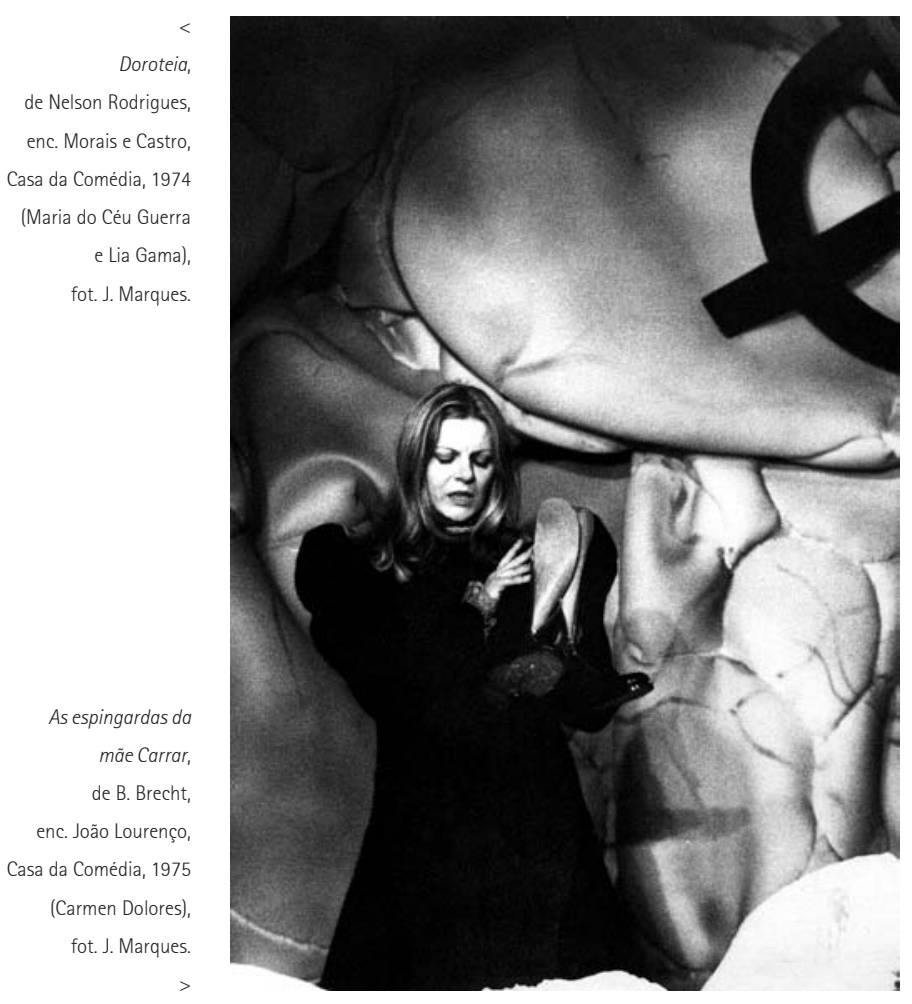

(1966), é consubstanciado na realização de As cem moedas de oiro, de Michel Demuynck (Dezembro de 1970), O rapto das cebolinhas, uma comédia policial infantil de Maria Clara Machado (Março de 1971) e A cigarra e as formigas, de Isabel da Nóbrega (Dezembro de 1971). Numa altura em que este género de teatro vai ganhando cada vez mais adeptos e respeitabilidade, o grupo das Janelas Verdes vêse também envolvido nesta campanha. Mas a actividade mais significativa relacionada com o teatro para a infância é aquela que se integra na iniciativa "Ao encontro do teatro", desenvolvida de 1971 a 1974 em colaboração com o Instituto de Meios Audio-Visuais de Educação (I.M.A.V.E. $)^{10}$, e destinada a alunos do ensino primário e secundário. Levada a cabo na sede da Casa da Comédia e em vários liceus de Lisboa, a iniciativa envolveu actores como Carmen Dolores, Glicínia Quartin, Manuela de Freitas, Isabel de Castro, Irene Cruz, Clara Joana, Fernanda Alves, Graça Lobo, Norberto Barroca, Álvaro Benamor, Augusto de Figueiredo, Paulo Renato, Raul Solnado, Rui Mendes, Manuel Cavaco, entre muitos outros. Esta colaboração serve ainda para a Casa da Comédia estrear mais dois espectáculos: Mestre Gil vai às escolas e Escola de domadores, ambos escritos propositadamente por João Osório de Castro para esta iniciativa. Escola de domadores (1973/74) teve a particularidade de ser encenado por João Lourenço, que, sobre esta sua nova experiência teatral, declara ao Diário de Lisboa: "Estou a tratar este espectáculo com um carinho e um cuidado especiais, como se fosse

Instituição que irá mais tarde dar origem ao Instituto de Tecnologia Educativa.

"Anón., "Oh papá, pobre papá a caminho das 100 representações", Diório o mais importante da minha carreira. Vejo isto como uma experiência muito importante" ${ }^{11}$.

Pelo seu lado, o teatro de marionetas tem em Francisco Esteves o seu maior cultor. A convite de Fernando Amado, João Osório de Castro e Luís Sande Freire, o marionetista desenvolve ai a sua actividade, fazendo deste tipo de teatro também um dos interesses do grupo: desloca-se por todo o país, promovendo cursos e apresentando espectáculos.

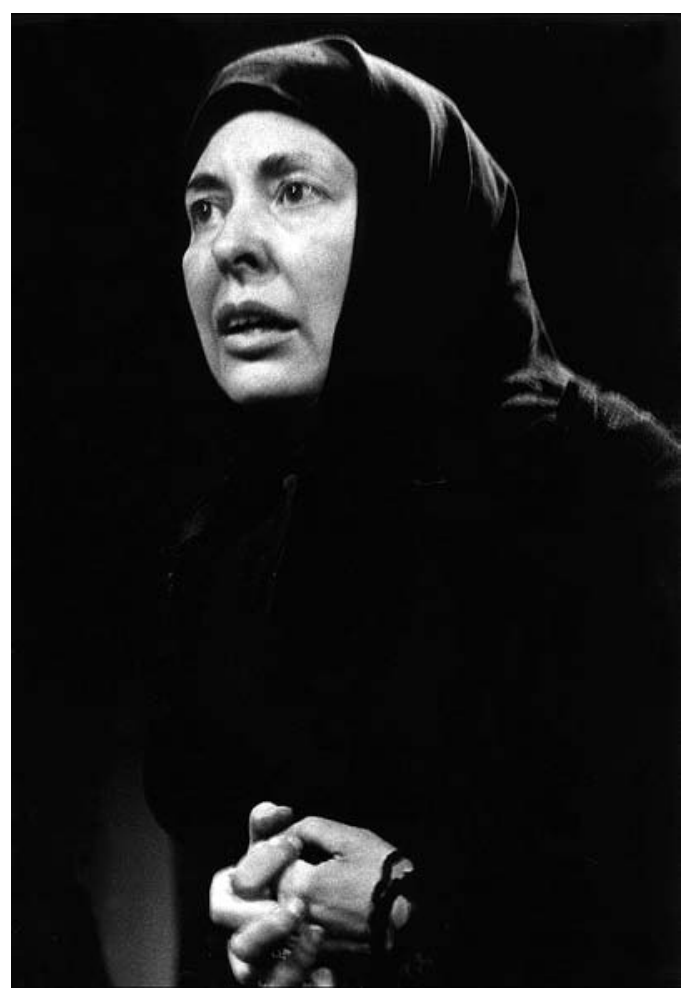

0 teatro para a infância e as marionetas são, assim, também uma face visível da actuação dinamizadora e culturalmente interventiva da Casa da Comédia, a par da sua actividade enquanto grupo de teatro experimental. Mas a sua linha programática e os interesses são alterados quando se dá o 25 de Abril. Corta-se com as linhas estéticas e culturais que tinham prevalecido até aí e, um pouco à semelhança do resto do panorama teatral português, rumase em direcção a um teatro de natureza mais política.

Em Julho de 1974, com a revolução acabada de estrear, Norberto Barroca regressa para encenar Um barco para Ítaca e outros poemas, de Manuel Alegre, um espectáculo de teatro, poesia e música. Com As espingardas da mãe Carrar, de Bertolt Brecht (Janeiro de 1975), a mudança de rumo é clara. 0 teatro épico, o teatro político, finalmente livre, chegava também à Casa da Comédia. A encenação é de João Lourenço - o primeiro dos vários Brecht que fará -, e possibilita a Carmen Dolores o seu primeiro Brecht, num espectáculo, contagiado pelo fervor pós-revolucionário, que não deixava esquecer que a vizinha Espanha ainda era governada por Franco.

Nesses anos de democracia recém-adquirida, nem a sociedade nem o teatro vão parar de mudar. $E_{\text {, }}$

consequentemente, a Casa da Comédia mudará também. A 18 de Junho de 1975, constitui-se em sociedade artística o Grupo de Trabalhadores da Casa da Comédia, com sede na Rua S. Francisco de Borja, n. ${ }^{\circ} 24$, com o objectivo de trabalhar para um público mais vasto e menos favorecido, usando preferencialmente textos portugueses, já teatralizados ou coligidos pelo grupo, e dando atenção ao contexto sócio-político.

A terceira fase de vida da Casa da Comédia encerravase aqui. Contudo, a Casa da Comédia, uma carvoaria feita teatro de bolso, um espaço para a prática do teatro que a ideia de Fernando Amado e a paciente dedicação de muitos outros ofereceram à cidade, essa, irá continuar ainda que noutras modalidades e com diferentes protagonistas. 


\section{$\mathrm{APCT}$ ाI, \\ Associação Portuguesa de Críticos de Teatro

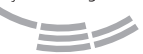

Presidente honorário

Direcção

Assembleia Geral

Conselho Fisca

ESTATUTOS

\section{Carlos Porto}

Maria Helena Serôdio

Paulo Eduardo Carvalho

Rui Cintra

Luiz Francisco Rebello

Fernando Midões

Ana Isabel Vasconcelos

Maria João Caetano

Mónica Guerreiro

Capitulo Primeiro (Da Associação e dos seus fins)

Art. ${ }^{\circ} 2{ }^{\circ}$

A Associação tem por objectivo:

Dignificar, estruturar e responsabilizar a actividade crítica relativa à teoria e prática do teatro, entendendo-se por actividade crítica não só a crítica de espectáculos, mas também tudo aquilo que diga respeito à informação, reflexão e teorização no campo das artes performativas.

Colaboração com Sinais de cena

A revista está aberta à participação de quem deseje colaborar enviando artigos que julgue corresponderem aos objectivos da publicação e às modalidades enunciadas pelas rubricas existentes. A consulta do sítio da APCT na Internet (www.apcteatro.org) e o contacto por correio electrónico (geral@apcteatro.org ou estudos.teatro@fl.ul.pt) são indispensáveis para conhecer as normas de apresentação dos artigos (dimensão, aspecto gráfico, citações, referências bibliográficas, ilustrações, etc.).

\section{ASSINATURA}

Desejo subscrever os números 7 e 8 da revista Sinais de cena (correspondentes a Junho e Dezembro de 2007), no valor total de $22,00 €$ beneficiando assim de um desconto sobre o preço de venda ao público.

Fora do pais: Europa $24,00 €$ / Fora da Europa $26,00 €$.

Nome:

Morada:

\begin{tabular}{l|l} 
Código postal: & Pais:
\end{tabular}

Endereço electrónico:

\begin{tabular}{ll|l} 
Forma de pagamento: $\square$ Vale postal $\square$ Cheque no. & Banco \\
\hline
\end{tabular}

(passar à ordem de Associação Portuguesa de Críticos de Teatro)

Preencha e envie este cupão (ou fotocópia do mesmo) para:

Data:

Sinais de cena

Centro de Estudos de Teatro

Faculdade de Letras de Lisboa: sala 67

Alameda da Universidade

1600-214 Lisboa (Portugal) 